\title{
ISOTRETINOÍNA NO TRATAMENTO DA ACNE: RISCOS E BENEFÍCIOS
}

\author{
ISOTRETINOIN IN ACNE TREATMENT: RISKS AND BENEFITS
}

\author{
Grazielle Alves de Oliveira \\ Bacharel em Farmácia pela Faculdade de Almenara - ALFA. \\ E-mail: graziellealves68@yahoo.com.br \\ Cláudia Santos Lopes Ruas \\ Bacharel em Farmácia pela Faculdade de Almenara - ALFA. \\ E-mail: claudiaruas1@hotmail.com
}

\section{Luiza Gobira Lacerda}

Graduação em Farmácia e Habilitação em Bioquímica pela Fundação Universidade de Itaúna; Especialização em Farmacologia e Interação Medicamentosas pelo

Centro Universitário Internacional; Docente da Faculdade de Almenara - ALFA de Almenara - Minas Gerais. E-mail: lugobila@hotmail.com

\section{Viviane Amaral Toledo Coelho}

Bióloga pelo Centro de Ensino Superior de Juiz de Fora; Especialista em Solos e Meio Ambiente pela Universidade Federal de Lavras; Mestre e Doutora em Ciência do Solo pela Universidade Federal de Lavras. Docente da Faculdade de Almenara - ALFA de Almenara - Minas Gerais. E-mail: vivianeatc@yahoo.com.br

\section{Ednardo de Souza Nascimento}

Pedagogo e Mestre em Ciências da Saúde pela Universidade Estadual de Montes

Claros;

Docente da Faculdade de Almenara - ALFA de Almenara - Minas Gerais. E-mail: ednardonardim@hotmail.com 


\section{RESUMO}

O objetivo do estudo foi detectar os riscos e benefícios do uso de isotretinoína no tratamento da acne grave. O estudo constituiu uma revisão bibliográfica tendo como critério de inclusão, textos em português, publicados entre os anos de 2002 e 2018, excetuando a Portaria 344 de 12 de maio de 1998 que regulamenta a venda de medicamentos para o controle da Vigilância Sanitária. Os abrangeram-se um total de 30 trabalhos, onde após uma leitura seletiva e minuciosa foram antepostos 20 artigos, três dissertações, uma portaria e uma tese para compor a revisão bibliográfica. Sendo que 6 destes artigos e uma portaria foram selecionados para integrar a descrição dos resultados e discussão. Com uma gama de problemas causados pela acne vulgar, uma isotretinoína apresenta-se como o tratamento mais eficaz. A presença do medicamento indica boa eficácia, concomitantemente tem uma série de efeitos adversos expressivos que são difíceis de terminar o tratamento. O usuário deve estar seguro, concordar e assinar os Termos de Serviço e regularizar os mesmos, manter registros estatísticos e não estar em um processo de gravidez, devido ao fato da teratogenicidade.

Palavras-chave: Isotretinoína. Reação adversa. Uso Terapêutico. Toxicidade.

\section{ABSTRACT}

The aim of the study was to detect the risks and benefits of using isotretinoin in the treatment of severe acne. The study constituted a bibliographic review based on the search of articles corresponding to the proposed theme, based on the exclusion and inclusion statistics, doing studies on the years from 2002 to 2018, with reference to 1998 Portal 344, dated May 12 Regulating the sale of medicines for the control of Sanitary Surveillance. Thus, the results of a global research were a total of 30 papers, being a complete and detailed sample of 20 articles, three dissertations, a concierge and a version to compose a bibliographical review. Since 6 videos and a concierge were selected to integrate a description of the results and discussion. With a range of problems, acne vulgaris, an isotretinoin presents itself as the most effective treatment. The dose of the drug indicates good, concomitantly has a number of adverse effects that are permanent in treatment. The user must be secure, 
agree and sign the Terms of Service and regularize the data, maintain statistical records and be in a pregnancy process due to the fact of teratogenicity.

Key words: Isotretinoin. Adverse reaction. Therapeutic Use. Toxicity. INTRODUÇÃO

A acne é a patologia de pele mais comum em todo mundo, tendo o potencial de ocasionar efeitos psicológicos prejudiciais no paciente, o que, assim sendo, aumenta a procura por tratamentos mais efetivos para a doença (ALVES; ORSOLIN; ROCHA, 2015). Segundo Silva et al. (2014) a acne pode ser conceituada como "uma doença genético-hormonal, auto limitada, de localização pilossebácea, com formação de comedões, pápulas e cistos, tendo sua evolução um processo inflamatório de maior intensidade, levando à formação de pústulas e abscesso, com freqüente êxito cicatricial." Essa doença se manifesta em $80 \%$ da população jovem, e de acordo com os dados do IBGE (Instituto Brasileiro de Geografia e Estatística) (2009) no Brasil 18 milhões de pessoas com idade entre 13 e 23 anos de idade, são acometidas com essas manifestações na pele.

De acordo com Damascena e Pereira (2017), existem diversas formas de tratamento para a acne, sendo o mais comum, o uso de antimicrobianos, retinóides (como a isotretinoína) e agentes abrasivos. Sendo que a isotretinoína é um medicamento derivado do retinol, mais usualmente conhecida como vitamina $A$.

A estrutura molecular da vitamina A foi determinada em 1931 por Karrer e colaboradores que propuseram o nome de axeroftol para a mesma, baseado na ação preventiva da vitamina A contra a xeroftalmia, uma afecção caracterizada pelo ressecamento e espessamento da conjuntiva. Posteriormente foi empregada para o tratamento da acne severa em que sua ação possui comprovadamente alta eficácia (DINIZ et al., 2002).

Nesta perspectiva, compreende-se que, a isotretinoína é o único composto oral eficaz para o tratamento dos tipos mais graves da acne, visto que extingue os fatores fisiopatológicos da doença. Quanto aos aspectos históricos, a isotretinoína foi elaborado em 1955 e introduzido no Brasil na década de 1980, tendo o fármaco como ação principal atuar inibindo o tamanho e a função de glândulas sebáceas e, posteriormente, o aparecimento das lesões cutâneas ocasionadas pelo acúmulo do sebo (ALVES; ORSOLIN; ROCHA, 2015). 
Considerando que a isotretinoína é a substância ativa do Roacutan $\AA$,um estereoisômero sintético do ácido all-trans-retinóico (tretinoína), seu mecanismo de ação ainda não foi elucidado em detalhes, mas já se estabeleceu que a melhora observada no quadro clínico da acne grave está associada à supressão da dose dependente da atividade da glândula sebácea e à redução do tamanho das glândulas sebáceas demonstrada histologicamente. Pode-se afirmar que a isotretinoína apresenta efeito antiinflamatório dérmico característico sendo o tempo de ação especifico para cada paciente. O tempo médio de início de ação farmacológica com resultado clínico é variável, mas estimado entre oito e dezesseis semanas (BRASIL, 2018).

O fármaco pesquisado apresenta eficácia constatada elevada, apesar de apresentar efeitos adversos expressivos, que freqüentemente dificultam o término do tratamento. Como efeitos prejudiciais associados ao uso da isotretinoína oral, estudos relatam que na maioria das vezes o paciente apresenta alterações bioquímicas como o aumento sérico das taxas de colesterol, triglicérides, aminotransferases e relacionados à pele, alteração nas mucosas, sistema nervoso, hematopoiético, musculoesquelético, gastrintestinal, cardiorrespiratório e geniturinário. Além dessas reações, "a isotretinoína possui efeito teratogênico sendo contraindicado para o uso em gestantes". Outros efeitos colaterais apresentados, como o ressecamento muco cutâneos são considerados temporários e com a interrupção da medicação os efeitos desaparecem (DAMASCENA; PEREIRA, 2017).

Ademais, o controle da farmacoterapia deve estar acompanhado dos exames laboratoriais que devem ser realizados em todas as etapas do tratamento, sendo que uma das características do tratamento da isotretinoína é alterar as enzimas hepáticas e a taxa de colesterol acima de $400 \mathrm{mg} / \mathrm{dl}$. O medicamento deve ser suspenso temporariamente até a normalização dos níveis séricos. Nesse contexto, o farmacêutico é o profissional da saúde apto a realizar o acompanhamento farmacoterapêutico, constituindo-se como ator no tocante ao seu papel para os usuários da isotretinoína, em relação às orientações quanto aos efeitos adversos mais comuns que podem ocorrer durante o uso desse medicamento e informação ao paciente sobre o Termo de Esclarecimento e Responsabilidade (TER) no ato da dispensação (SETTE et al., 2009). 
A pesquisa justifica-se em razão da necessidade de maiores estudos voltados ao conhecimento do fármaco isotretinoína, sobretudo pela difusão da sua utilização no tratamento para a acne grave entre jovens. Considerando-se que é um medicamento com numerosas reações adversas, devendo seu uso ser recomendado por especialista. Devido a especificidade da sua formação, vale destacar a participação do farmacêutico na intervenção do uso desse fármaco, atuando junto ao paciente no âmbito da atenção farmacêutica sobre os possíveis efeitos adversos, possibilitando a redução desses riscos e uma melhor adesão ao tratamento através de uma farmacoterapia efetiva. O objetivo central do trabalho foi o de identificar e descrever através da pesquisa bibliográfica os riscos e benefícios do tratamento de acne grave com o uso da isotretinoína.

\section{METODOLOGIA}

A metodologia aplicada foi a revisão bibliográfica, que consiste em analisar amplamente a literatura observando e discutindo sobre métodos, resultados e conclusões gerais sobre o tema escolhido para pesquisa, assim como embasar e possibilitar fomento científico para futuras pesquisas relacionadas ao assunto em questão (MINAYO, 2007).

A busca de dados foi precedida da seguinte pergunta norteadora: Quais as reações adversas mais prevalentes e os riscos associados ao uso de isotretinoína oral para o tratamento de acne? Foi realizado o levantamento bibliográfico de artigos científicos, do ano de 2002 a 2018, tendo apenas uma referência de 1998 sendo a Portaria 344, de 12 de maio de 1998 que regulamenta a venda de medicamentos sujeitos a controle da Vigilância Sanitária. As pesquisas foram feitas nas bases de dados eletrônicas: Scientific Eletronic Library Online (SCIELO), Biblioteca Virtual em Saúde (BVS) e Google Acadêmico. Durante a pesquisa, foram utilizados os seguintes descritores segundo o DeCS: acne vulgar, isotretinoína, reação adversa.

Foram adotados como critérios de inclusão: relevância ao tema, publicações em português, atualidade das informações contidas no artigo e artigos relacionados com o uso de isotretinoína para o tratamento de acne e as reações adversas apresentadas.

Desta forma, a seleção final abrangeu um total de 30 trabalhos, onde após uma leitura seletiva e minuciosa foram antepostos 20 artigos, três dissertações, uma 
portaria e uma tese para compor a revisão bibliográfica. Sendo que 6 destes artigos e uma portaria foram selecionados para integrar a descrição dos resultados e discussão.

\section{ACNE: CONCEITO E EPIDEMIOLOGIA}

A acne é uma patologia frequente na população em geral, atingindo principalmente adolescentes e adultos jovens. É uma doença que se manifesta em vários graus de intensidade $e$, tendo a face como local de manifestação mais comum. Caracterizada por alteração fisiopatológica, a acne pode gerar problemas paralelos tais como: depressão, redução da autoestima, e até discriminação social (BRITO et al., 2010). Diante do exposto, pode-se dizer que a acne em adolescentes é totalmente diferente, pois é possível encontrar o predomínio de pápulas e pústulas com total ausência de comedões. Antes identificados como uma erupção acneiforme e não como acne verdadeira, seu aparecimento em geral, estava relacionado a fatores externos como: o uso de drogas, cosméticos em demasia, produtos químicos, entre outros (BOUZAS; MENESES, 2009).

É importante ressaltar que, a acne vulgar é a doença cutânea mais freqüente que acomete de 85 a 100\% da população em algum momento da vida. Sendo caracterizada por lesões que resultam da ação dos hormônios sobre as glândulas sebáceas da pele, afetando as áreas com maior densidade de folículos sebáceos (MENDES et al., 2016)

Segundo Silva et al. (2014) a acne é uma doença genético-hormonal, autolimitada, de localização polissebácea com formação de comedões, pápulas e cistos, sua evolução soma um processo inflamatório de maior intensidade levando a formação de pústulas e abscessos, com frequente êxito cicatricial. Existem quatro fatores determinantes da acne: hipersecreção das glândulas sebáceas, alteração no processo de queratinização, colonização do folículo piloso por micro-organismos, nomeadamente Propionibacterium acnes e Staphylococcusalbus e liberação de mediadores inflamatórios na pele (KOLBE; SILVA, 2017).

Neste contexto, sabe-se que essa doença é um problema muito comum em 80\% da população jovem, e de acordo com os dados do IBGE (2009) no Brasil 18 milhões de pessoas com idade entre 13 e 23 anos de idade, são acometidas com 
essas manifestações na pele. Vale ressaltar que segundo a Sociedade Brasileira de Dermatologia (SBD) em 2010, estimou que a acne tenha afetado 650 milhões de pessoas à escala global, correspondendo a 9,4\% da população, situando-a como a $8^{\underline{a}}$ doença mais comum em todo mundo.

Em um estudo conduzido por Brito et al. (2010), realizado no ambulatório de Dermatologia do Centro Integrado de Saúde Amauri de Medeiros (CISAM) em Recife, dos 150 pacientes com acne estudados, 72 (48\%) eram do sexo feminino e $78(52 \%)$ do sexo masculino. A idade variou de 15 a 32 anos, sendo $29 \%$ deles menores de 18 anos, 56\% com idade entre 18 e 25 anos e 15\% maiores de 25 anos. Quanto aos efeitos colaterais cutâneos mucosos da isotretinoína, queilite foi o mais frequente acontecendo em 141 (94\%) pacientes, em seguida xerodermia em 71 $(47,3 \%)$ pacientes e ressecamento de mucosas em 70 (46,7\%). A queilite é caracterizada como um processo inflamatório localizado no ângulo da boca uni ou bilateral, caracterizado por discreto edema, descamação, erosão e fissuras. E a xerodermia ou secura da pele é uma manifestação exócrina caracterizada pelo fato de as glândulas sebáceas e sudoríparas produzirem deficientemente as secreções que umedecem e lubrificam a pele.

\section{FISIOPATOLOGIA DA ACNE}

Carvalho e Carvalho (2005) relatam que os hormônios andrógenos produzidos a partir do início da puberdade, favorecem a hipertrofia das glândulas sebáceas levando ao aparecimento de óstios dilatados, particularmente nas áreas que apresentam maior quantidade de unidades pilossebáceas. Os andrógenos também determinam o incremento na produção sebácea por estas glândulas, clinicamente representado pelo estado de oleosidade cutânea e instalação da acne.

O que se percebe é que as lesões acneicas inflamatórias costumam estar relacionadas à presença do agente Propionibacterium acnes no interior da glândula. Esta bactéria instala-se na glândula sebácea e seu metabolismo enzimático promove, por hidrólise dos triglicerídeos, a liberação de substâncias irritantes que, por sua vez, atuam como quimiotáticos para as células do sistema imunológico. Quando instaurado esse quadro é constante a verificação de pápulas inflamatórias, pústulas, nódulos e cistos inflamatórios, sinais que caracterizam uma acne de 
moderada a severa. Soma-se a isso que a acne pode ser classificada em 4 tipos de acordo com o grau de severidade e localização, como consta na Figura 1. Apesar da gravidade do quadro evoluir do grau I para o grau IV, pode haver somatória de graduações diferentes de acne na formação dos quadros clínicos (CARVALHO; CARVALHO, 2005).

Figura 1. Quadro da classificação das Acnes.

\begin{tabular}{|c|c|c|}
\hline Tipo de Acne & Manifestações & Localização principal \\
\hline Grau I & $\begin{array}{c}\text { Comedões, oleosidade } \\
\text { da pele e poros } \\
\text { dilatados }\end{array}$ & Face \\
\hline Grau II & Pápulas e pústulas & Face \\
\hline Grau III & Nódulos e cistos & Face \\
\hline Grau IV & Nódulos e cistos & Face, colo e dorso \\
\hline
\end{tabular}

Fonte: (CARVALHO et al., 2005)

Neste viés pode-se categorizar que a unidade polissebácea na pele normal é constituída por glândulas sebáceas multilobulares, pelo rudimentar e canal folicular envolto de um epitélio escamoso estratificado. Compreende-se que desta forma o desenvolvimento dessas unidades é regulado por hormônios androgênicos e vários outros fatores biológicos. Os hormônios relacionados com a patogênese da acne são a de hidrotestosterona e testosterona, responsáveis por controlar a atividade das glândulas sebáceas (DINIZ et al., 2014).

\section{TRATAMENTO FARMACOLÓGICO DA ACNE}

O tratamento da acne pode ser feito por via oral ou por via tópica. $\mathrm{Na}$ atualidade, o tratamento mais comum para a acne de grau moderado a grave é feito com a isotretinoína oral. $\mathrm{O}$ tratamento da acne visa controlar os diferentes fatores que levam ao seu surgimento. Diante disso é possível identificar os objetivos principais da farmacoterapia dessa patologia, tratando-se de controlar a 
hiperceratose de retenção, reduzir a produção de sebo, diminuir a população bacteriana e eliminar a inflamação (KOLBE; SILVA, 2017).

O tratamento da acne deve ser o mais precoce possível para evitar cicatrizes físicas e psicossociais, para tanto o uso da isotretinoína revolucionou o tratamento da acne. Desta forma pode-se afirmar que a terapia com isotretinoína dura em média de 4 a 6 meses, e só é observado a diminuição da acne após 2 meses de uso e o benefício do tratamento permanece por alguns meses após o termino da intervenção medicamentosa (BRASIL, 2015).

Os estudos apontam que, os tratamentos tópicos e sistêmicos, que não a isotretinoína (antibióticoterapia e antiandrogênicos), para a acne vulgar nas mulheres costumam ser efetivos na melhora dos casos mais leves desta manifestação, principalmente quando os objetivos terapêuticos são os de corrigir as alterações metabólicas. Apesar disto o índice de recorrência e a dificuldade terapêutica quando relacionada a uma acne mais severa pode estar presente. Diante de tal constatação, a terapêutica da acne deve ser adequada à gravidade e morfologia das lesões sendo de suma importância o acompanhamento por um dermatologista e um farmacêutico auxiliando na prevenção e solucionando possíveis interações, e consequentemente monitorar e minimizar reações adversas ao fármaco da terapia medicamentosa (CARVALHO; CARVALHO, 2005).

\section{ISOTRETINOÍNA E CARACTERÍSTICAS ESTRUTURAIS}

Definida como um ácido 13-cis-retinóico, pode-se afirmar que a isotretinoína é um fármaco pertencente à classe dos retinóides, também conhecidos como derivados da vitamina A. Soma-se a isso o fato de o termo retinóides ser empregado a essa classe de compostos, cuja estrutura química consiste em "quatro grupos isoprenóides ligados de modo cabeça-cauda. Essa formação possui um anel não aromático de seis átomos de carbono com uma cadeia lateral poliprenóide, que é ter minada com um grupo funcional formado de carbono e oxigênio, na maioria das vezes" (DAMASCENA; PEREIRA 2017).

Esta substância tem peso molecular de 300,44g, apresenta-se como um pó cristalino amarelo a amarelo claro e é solúvel no cloreto de metileno, ligeiramente solúvel no álcool e insolúvel na água (DINIZ et al., 2002). 
No seu espectro de ação, a isotretinoína atua como uma espécie de hormônio e desenrola sua atividade biológica após se ligar e ativar os receptores do ácido retinóico (RAR) e os receptores retinóides $X(R X R)$. Em consonância com os princípios e objetivos desse retinóide se alia aos fatores de transcrição e complexo ligante-receptor que se une a regiões promotoras dos genes-alvo promovendo a regulação de sua expressão, induzindo ou suprimindo a transcrição gênica. O RNA mensageiro já transcrito passa para o citoplasma e no ribossomo induz a síntese do material protéico que regula a proliferação, diferenciação celular, a inflamação e o funcionamento das glândulas sebáceas (BORGES et al., 2011).

A ação principal do fármaco é diminuir a produção de sebo; o tamanho da glândula sebácea diminui e acontece uma alteração na estrutura e na capacidade secretória das células. Ocorre em cerca de $90 \%$ dos casos a redução completa das lesões (KNUTSON; PERSHING, 2004).

O medicamento em questão apresenta uma eficácia sobre quatro irregularidades da acne, como redução do tamanho das células das glândulas sebáceas e impede a sua atividade reduzindo assim a produção de sebo, aumentando a separação das células foliculares polissebáceas. Afeta o processo de queratinização, diminui a quantidade de queratina. Faz com que os desmossomos fiquem menores e menos desenvolvidos. Daí então o extrato córneo se torna menos organizado e mais fino pela perda das camadas superficiais. Devido a esses efeitos reduz significamente o crescimento das bactérias nas lesões e diminui a inflamação (MENDES et al., 2016).

De acordo com Cajueiro, Lima e Partata (2014), as concentrações plasmáticas da isotretinoína após a administração por via oral podem ser atingidas em cerca de duas a quatro horas. Uma vez que o fármaco é toleravelmente mais bem absorvido no trato gastrointestinal quando há a presença de alimento, promovendo o retardo do esvaziamento gástrico e aumentando o tempo de permanência da droga no organismo.

Pode-se entender que a isotretinoína é metabolizada pelo processo de oxidação através das enzimas do citocromo P450 presentes na parede do estômago, originando três metabólitos: a 4-oxi-isotretinoína, tretinoína e 4-oxotretinoína, que se acumula no sangue a partir de seguidas administrações. Ela é excretada pela bile após passar pela conjugação com o ácido glicurônico. Os outros 
metabólitos são lentamente depositados no plasma e possui meia-vida de eliminação de 25 horas. Sendo assim o tempo de meia vida é de 7 a 39 horas, estabelecido pelas administrações repetidas e apresenta sua excreção por via urinária (CAJUEIRO; LIMA; PARTATA, 2014).

\section{REAÇÕES ADVERSAS ASSOCIADAS AO USO DE ISOTRETINOÍNA ORAL E CONTRAINDICAÇÕES}

Apesar da sua efetividade no controle da acne, a isotretinoína tem apresentado vários efeitos adversos, como alterações mucocutâneos e efeitos tóxicos sistêmicos, no qual os mais comuns são: queilite, ressecamento da pele do corpo, aumento do colesterol, triglicerídeos e enzimas hepáticas. Portanto são necessários exames laboratoriais antes e durante o tratamento, afim de monitorar uma possível alteração no perfil lipídico, sendo esse um efeito colateral comum ao uso da isotretinoína.

Estudo de corte populacional mostrou que a elevação de triglicerídeos ocorreu em $45 \%$ dos pacientes durante o tratamento, enquanto que aumento de colesterol total foi encontrado em 30\% deles (35). Geralmente essas elevações são leves e não determinam a interrupção do tratamento. Os efeitos adversos causados pela utilização desse medicamento podem ser minimizados com sua redução, com exceção da teratogenicidade (CAJUEIRO; LIMA; PARTATA, 2014).

Os efeitos adversos associados ao tratamento da acne com o uso da isotretinoína podendo ser divididos em duas classes: efeitos mucocutâneos e efeitos tóxicos sistêmicos. Usualmente, pacientes que usam isotretinoína oral manifestam ressecamento e fissuras nos lábios, pele e mucosas em vista da diminuição da produção de sebo. Além de reduzir a espessura do estrato córneo que provoca foto sensibilidade, blefaroconjuntivite; também é observado prurido, descamação da pele e dermatite (BRITO et al., 2010).

Kolbe e Silva (2017) corroboram com o fato de que a isotretinoína é uma medicação segura e o único risco irreversível é, em mulheres, a ação teratogênica. É imprescindível que as mulheres realizem teste de gravidez antes de iniciar o tratamento com essa medicação. Incluem no grupo das contra-indicações relativas ao uso da isotretinoína a obesidade com distúrbio de colesterol ou triglicérides; 
diabetes insulinodependente; doença hepática, renal ou sistêmica; epilepsia, depressão e psicose. Para o controle dessas condições devem ser realizados exames clínicos e laboratoriais mensais.

\section{RESULTADOS E DISCUSSÃO}

Entre os artigos integrados na revisão, quatro foram revisão de literatura, um elaborado por acadêmicos do curso de Farmácia com orientação de um dermatologista que concordou em participar da pesquisa depois de serem feitas todas as análises correspondente ao uso da isotretinoína com consentimento dos pacientes, um descrito através de um estudo feito por meio de levantamento de dados através de receitas de controle especial, e uma legislação que regulamenta a venda de medicamentos sujeito a controle da Vigilância Sanitária (Tabelas 1 e 2).

Tabela 1: Informações dos artigos incluídos na revisão bibliográfica.

\begin{tabular}{|c|c|c|c|}
\hline Título & Periódico & Pais de publicação & Idioma \\
\hline $\begin{array}{l}\text { Avaliação dos potenciais } \\
\text { efeitos adversos em } \\
\text { pacientes em uso de } \\
\text { isotretinoína oral para o } \\
\text { tratamento de acne } \\
\text { vulgar: Uma revisão } \\
\text { Bibliográfica }\end{array}$ & $\begin{array}{l}\text { Revista Multidisciplinar e de } \\
\text { Psicologia, v. } 11, \text { n. } 35, \\
\text { maio, } 2017\end{array}$ & Brasil & Português \\
\hline $\begin{array}{l}\text { Acompanhamento } \\
\text { fármaco terapêutico do } \\
\text { uso da isotretinoína: um } \\
\text { estudo de caso }\end{array}$ & $\begin{array}{l}\text { Faculdade Montes Belos } \\
\text { (FMB), v. 7, n.1, p. 121-135, } \\
2014 .\end{array}$ & Brasil & Português \\
\hline $\begin{array}{l}\text { Isotretinoína e suas } \\
\text { propriedades } \\
\text { farmacológicas }\end{array}$ & $\begin{array}{l}\text { Revista Científica } \text { do } \\
\text { ITPAC, v. } 7 \text {, n. 1, p. 1-16, } \\
\text { jan, } 2014\end{array}$ & Brasil & Português \\
\hline $\begin{array}{l}\text { Isotretinoína no } \\
\text { tratamento da acne: } \\
\text { riscos } x \text { benefícios }\end{array}$ & $\begin{array}{l}\text { Revista Brasileira } \\
\text { Farmacêutica, v. 90, n. 3, p. } \\
\text { 186-189, } 2009 .\end{array}$ & Brasil & Português \\
\hline Atenção farmacêutica e o & Instituto Pharmacológica. & Brasil & Português \\
\hline
\end{tabular}




\begin{tabular}{l|l|l|l}
\hline uso da isotretinoína & Goiânia, 1997. & & \\
\hline Efeitos do uso da & Arquivo Brasileiro de & Brasil & Português \\
Isotretinoína e Acitretina & Odontologia, v.12 n.1, 2016 & & \\
nos tecidos bucais - & & \\
Revisão de Literatura & & & \\
\hline Aprova o Regulamento & Portaria n.. 344, de 12 de & Brasil & Português \\
Técnico sobre & maio de 1998. & & \\
substâncias e & & & \\
medicamentos sujeitos a & & & \\
controle especial & & & \\
\hline
\end{tabular}

Tabela 2: Caracterização da síntese dos artigos incluídos na revisão bibliográfica.

\begin{tabular}{|c|c|c|c|c|}
\hline Artigo & Objetivos & Metodologia & Resultados & $\begin{array}{l}\text { Potenciais de riscos e } \\
\text { benefícios da } \\
\text { Isotretinoína oral }\end{array}$ \\
\hline \multirow[t]{2}{*}{ Artigo 1} & $\begin{array}{l}\text { Identificar através } \\
\text { de minuciosa } \\
\text { pesquisa } \\
\text { bibliográfica os } \\
\text { potências efeitos } \\
\text { adversos do } \\
\text { tratamento de } \\
\text { acne vulgar com a } \\
\text { isotretinoína }\end{array}$ & $\begin{array}{l}\text { Este estudo } \\
\text { consiste em uma } \\
\text { revisão } \\
\text { bibliográfica, que } \\
\text { permite analisar a } \\
\text { literatura, } \\
\text { observando e } \\
\text { discutindo sobre } \\
\text { métodos, } \\
\text { resultados } \\
\text { conclusões } \\
\text { relacionados ao } \\
\text { assunto em } \\
\text { questão. }\end{array}$ & $\begin{array}{l}\text { Ao final do estudo } \\
\text { verificou-se que } \\
\text { os indivíduos que } \\
\text { faziam o uso da } \\
\text { isotretinoína oral } \\
\text { como uma terapia } \\
\text { contra a acne } \\
\text { apresentaram } \\
\text { várias reações } \\
\text { adversas. }\end{array}$ & $\begin{array}{l}\text { Os autores } \\
\text { evidenciaram que as } \\
\text { reações adversas em } \\
\text { pacientes com o uso da } \\
\text { isotretinoína oral no } \\
\text { tratamento da acne } \\
\text { mais comuns são: } \\
\text { queilite, xerodermia e } \\
\text { ressecamento das } \\
\text { mucosas; embora } \\
\text { apresente essas } \\
\text { reações, a isotretinoína } \\
\text { possui uma terapia } \\
\text { efetiva contra a acne. }\end{array}$ \\
\hline & $\begin{array}{l}\text { Objetiva um } \\
\text { estudo de caso de } \\
\text { acompanhamento } \\
\text { fármaco } \\
\text { terapêutico clínico } \\
\text { fundamentado no }\end{array}$ & $\begin{array}{l}\text { Foi realizado um } \\
\text { estudo de caso } \\
\text { de } \\
\text { acompanhamento } \\
\text { fármaco } \\
\text { terapêutico clínico }\end{array}$ & $\begin{array}{l}\text { Os resultados } \\
\text { obtidos } \\
\text { estão de } \\
\text { acordo com } \quad \text { c } \\
\text { conceito } \quad \text { de } \\
\text { farmácia clínica e } \\
\text { de } \quad \text { atenção }\end{array}$ & $\begin{array}{l}\text { Apesar de não } \\
\text { acompanhar os } \\
\text { pacientes até o final do } \\
\text { tratamento, contudo do } \\
\text { ponto de vista técnica, } \\
\text { este estudo concorda }\end{array}$ \\
\hline
\end{tabular}




\begin{tabular}{|c|c|c|c|c|}
\hline Artigo 2 & $\begin{array}{l}\text { Método Dáder no } \\
\text { qual foi elaborado } \\
\text { um formulário }\end{array}$ & $\begin{array}{l}\text { fundamentado no } \\
\text { Método Dáder } \\
\text { para a coleta de } \\
\text { dados do } \\
\text { voluntário antes e } \\
\text { durante o } \\
\text { tratamento de } \\
\text { quatro meses. }\end{array}$ & $\begin{array}{l}\text { farmacêutica, } \\
\text { Respaldado pela } \\
\text { RDC 44/2009 } \\
\text { (Resolução da } \\
\text { Diretoria } \\
\text { Colegiada). }\end{array}$ & $\begin{array}{l}\text { com o conceito de } \\
\text { farmácia clínica e de } \\
\text { atenção farmacêutica. }\end{array}$ \\
\hline Artigo 3 & $\begin{array}{l}\text { Descrever as } \\
\text { propriedades } \\
\text { químicas e físicas } \\
\text { da isotretinoína, } \\
\text { bem como } \\
\text { farmacocinética e } \\
\text { farmacodinâmica, } \\
\text { relacionar suas } \\
\text { reações adversas } \\
\text { mais freqüentes. }\end{array}$ & $\begin{array}{l}\text { Este estudo trata } \\
\text { de uma revisão } \\
\text { de literatura de } \\
\text { caráter descritivo } \\
\text { e exploratório. }\end{array}$ & 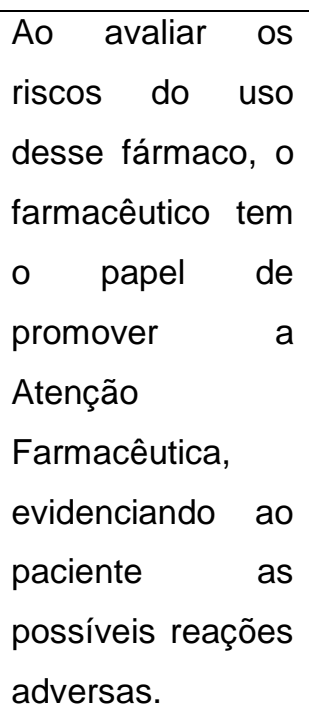 & $\begin{array}{l}\text { Os autores salientaram } \\
\text { que as reações } \\
\text { adversas ocasionadas } \\
\text { pela administração da } \\
\text { droga são } \\
\text { potencialmente graves, } \\
\text { principalmente quando } \\
\text { se evidencia seu poder } \\
\text { teratogênico. }\end{array}$ \\
\hline Artigo 4 & $\begin{array}{l}\text { Teve como } \\
\text { objetivo avaliar a } \\
\text { existência de } \\
\text { monitoramento do } \\
\text { tratamento com } \\
\text { isotretinoína e } \\
\text { detectar possíveis } \\
\text { reações adversas } \\
\text { em pacientes } \\
\text { submetidos ao } \\
\text { tratamento. }\end{array}$ & $\begin{array}{l}\text { A pesquisa foi } \\
\text { realizada através } \\
\text { de levantamento } \\
\text { de dados de } \\
\text { receitas de } \\
\text { controle especial } \\
\text { e de entrevista } \\
\text { com pacientes } \\
\text { submetidos ao } \\
\text { tratamento com } \\
\text { isotretinoína que } \\
\text { fizeram aquisição } \\
\text { do medicamento } \\
\text { na Drogaria } \\
\text { Redefharma. } \\
\text { Delivery Prata, } \\
\text { em Campina }\end{array}$ & $\begin{array}{l}\text { Observou que } \\
\text { mais da metade } \\
\text { dos participantes } \\
\text { foram do gênero } \\
\text { feminino (65\%) a } \\
\text { faixa etária mais } \\
\text { frequente foi } \\
\text { aquela entre } 14 \text { e } \\
20 \text { anos. Cerca } \\
\text { de } 90 \% \text { dos } \\
\text { pacientes } \\
\text { estavam em uso } \\
\text { da isotretinoína } \\
\text { para o tratamento } \\
\text { da acne. O } \\
\text { restante para } \\
\text { tratamento }\end{array}$ & $\begin{array}{l}\text { De acordo com os } \\
\text { autores, verificou-se que } \\
\text { a monitorização ainda é } \\
\text { falha, podendo levar a } \\
\text { vários fatores de risco, } \\
\text { como má formação fetal } \\
\text { em mulheres grávidas, } \\
\text { alterações em órgãos; } \\
\text { devido a isso, a relação } \\
\text { riscos e benefícios } \\
\text { devem ser } \\
\text { minuciosamente } \\
\text { avaliados. }\end{array}$ \\
\hline
\end{tabular}


Revista Multidisciplinar do Nordeste Mineiro, v1. 2020/01

ISSN 2178-6925

\begin{tabular}{|c|c|c|c|c|}
\hline & & Grande, PB. & rejuvenescedor. & \\
\hline Artigo 5 & $\begin{array}{lr}\text { Apresentar } & \text { a } \\
\text { importância } & \text { da } \\
\text { atenção } & \\
\text { farmacêutica } & \text { na } \\
\text { dispensação } & \text { da } \\
\text { Isotretinoína. } & \end{array}$ & $\begin{array}{l}\text { Revisão de } \\
\text { literatura. }\end{array}$ & $\begin{array}{l}\text { A realização de } \\
\text { mais pesquisas } \\
\text { nessa área se faz } \\
\text { necessária, para } \\
\text { a constate alerta } \\
\text { da população aos } \\
\text { riscos provocados } \\
\text { pelo uso da } \\
\text { Isotretinoína. }\end{array}$ & $\begin{array}{l}\text { Apesar dos ricos } \\
\text { avaliados, } \\
\text { Isotretinoína representa } \\
\text { um grande avanço para } \\
\text { o tratamento da acne. }\end{array}$ \\
\hline Artigo 6 & $\begin{array}{l}\text { O objetivo deste } \\
\text { estudo é buscar } \\
\text { na literatura } \\
\text { cientifica, } \\
\text { evidencias sobre } \\
\text { os efeitos } \\
\text { colaterais na } \\
\text { cavidade bucal } \\
\text { em indivíduos } \\
\text { usuários de } \\
\text { isotretinoína }\end{array}$ & $\begin{array}{l}\text { Este estudo } \\
\text { consiste em uma } \\
\text { revisão de } \\
\text { literatura que } \\
\text { aborda os efeitos } \\
\text { do uso da } \\
\text { isotretinoína nos } \\
\text { tecidos bucais. }\end{array}$ & $\begin{array}{l}\text { Os resultados } \\
\text { obtidos } \\
\text { demonstram que } \\
\text { a isotretinoína é } \\
\text { um dos retinoídes } \\
\text { sintéticos que } \\
\text { representam o } \\
\text { grupo mais } \\
\text { potente de } \\
\text { queratolíticos. }\end{array}$ & $\begin{array}{l}\text { Identificou-se que a } \\
\text { queilite é a } \\
\text { manifestação mais } \\
\text { freqüentemente relatada } \\
\text { nos tecidos bucais. }\end{array}$ \\
\hline Artigo 7 & 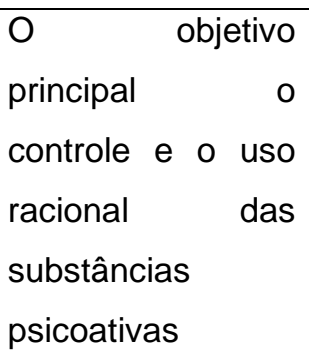 & - & - & - \\
\hline
\end{tabular}

Fonte: Os autores. 
Os estudos 1, 3, 5 e 6 são de abordagem descritiva, e utilizaram-se do método de revisão de literatura através de buscas sistematizadas das principais bases de artigos científicos relacionados ao uso da isotretínoina oral no tratamento da acne e seus principais efeitos adversos.

No estudo 2 o paciente analisado estava sendo acompanhado por um médico dermatologista e o estudo 4 foi construído a partir de levantamento de dados de receitas de controle especial e de entrevistas com pacientes que fizeram aquisição da isotretinoína em uma drogaria. O artigo 7 é a portaria 344 de 12 de maio de 1998 que regulamenta o medicamento isotretinoína.

No final do estudo 1 pode se concluir que as reações adversas corriqueiras são a queilite, xerodermia e ressecamento das mucosas, destacando também as alterações sistêmicas que ocorre em minoria dos pacientes que fazem o uso da isotretinoína. Tal resultado corrobora com os estudos de Brito et al., (2010) de que 94\% da população apresenta queilite seguido de xerodermia.

No artigo 2 foi realizado um acompanhamento farmacoterapêutico na qual foi utilizado um formulário para coleta de dados do paciente durante o período de 4 meses de tratamento com o medicamento. Ao analisar os resultados obtidos, foi possível verificar que o paciente manifestou um quadro clínico sem grandes alterações farmacológicas e bioquímicas; como afirma Damascena e Pereira (2017) que apesar dos efeitos adversos estarem presentes durante todo o tratamento, são considerados temporários, uma vez que com uma interrupção do medicamento os efeitos desaparecem.

No artigo 3 foi salientado que as reações adversas ocasionadas pela administração da isotretinoína são potencialmente graves, dentre essas reações destacou-se a teratogenicidade.

No estudo 4 foi feito uma pesquisa em uma drogaria com 20 pacientes que fizeram compra do medicamento no referido estabelecimento no período de 6 meses. Para isso foi utilizado como instrumento de coleta de dados, questionários preenchidos à partir da análise das prescrições médicas dos pacientes, juntamente com as entrevistas no ato da compra. Percebeu-se que $65 \%$ dos participantes foram do gênero feminino, a faixa etária foi entre 14 e 20 anos, 90\% dos pacientes usavam a isotretinoína para tratamento da acne; o restante para tratamento rejuvenescedor. Dos pacientes entrevistados $80 \%$ tiveram esclarecimento da droga, entretanto $20 \%$ 
não tiveram nenhum esclarecimento sobre o medicamento.Dessa forma Selte et al., (2009) destacam que o farmacêutico é o profissional da saúde apto a realizar acompanhamento farmacoterapêutico, que se torna muito importante para o usuário da isotretinoína em relação as orientações quanto as reações adversas durante o tratamento.

No artigo 5 destaca-se a importância da atenção farmacêutica durante o tratamento com a isotretinoína salientando a importância de realização de mais pesquisas nessa área, pois a população precisa constantemente ser alertada com relação aos riscos causados pela administração desse medicamento.

No artigo 6 os resultados obtidos demonstraram que a isotretinoína é um dos retinoídes sintéticos que apresentam o grupo mais potente dos queratolíticos e que a queilite é a manifestação mais frequente.

No $7^{\circ}$ artigo aborda-se a portaria 344 , de 12 de Maio de 1998 a qual regulamenta a comercialização da isotretinoína e demais medicamentos sujeitos a controle especial. Destaca-se em relação a Notificação de Receita, documento que autoriza a dispensação de medicamentos. No caso da isotretinoína deve ser o único medicamento contido nesta notificação e na prescrição. Utiliza-se a Notificação de Receita Especial (de cor branca) tendo validade por 30 dias a partir da data de sua emissão.

De acordo com a Portaria 344, de 12 de maio de 1998, que regulamenta medicamentos sujeitos a controle da Vigilância Sanitária, a isotretinoína pertence à lista de medicamentos "C2", e está sujeita a controle especial, só podendo ser comercializado mediante apresentação da prescrição médica, porém sem retenção da mesma. Para que uma drogaria seja autorizada a comercializar esse medicamento deverá ser realizado um credenciamento prévio validado pela Autoridade Sanitária Estadual (BRASIL, 1998).

As discussões comprovam a da eficácia do trabalho farmacêutico mediante o aumento da adesão dos pacientes aos protocolos de tratamentos, diminuindo custos nos sistemas de saúde pelo fato do monitoramento das reações e interações medicamentosas, o que reflete diretamente na qualidade de vida dos pacientes (CAJUEIRO; LIMA; PARTATA, 2014).

$E$ é nessa perspectiva que busca-se discutir a função do farmacêutico em relação à dispensação da isotretinoína, orientar o paciente, principalmente se for 
mulher em idade fértil, sendo necessário o acompanhamento através da atenção farmacêutica, onde o profissional estará apto a esclarecer todas as dúvidas do paciente, informando-o a respeito dos procedimentos de seu tratamento. Os estudos demonstram que o monitoramento tanto do médico quanto do farmacêutico representa segurança e sucesso no tratamento (FREITAS; SANTOS, 1997).

\section{CONCLUSÃO}

A acne vulgar apresenta-se como uma doença dermatológica extremamente comum, que se manifesta em maior proporção em adolescentes e jovens adultos. Refere-se de um processo crônico decorrente de uma maior alteração de hormônios masculinos, que pode ocasionar lesões em tipos de comedões (cravos), pústulas, pápulas, e mais gravemente pode gerar cistos, abscessos e cicatrizes em graus variáveis. Pela magnitude ocasionada pela acne vulgar, os indivíduos acometidos podem desenvolver reduções de autoestima, depressões, discriminações e estigmas sociais.

Dentre a amplitude de problemas acarretados pela acne vulgar, a Isotretinoína apresenta-se como o tratamento mais eficaz. Apesar de o fármaco denotar uma boa efetividade, concomitantemente é possuinte de uma série de efeitos adversos expressivos que frequentemente dificulta o término do tratamento. O paciente usuário deve estar ciente, concordar e assinar os Termos de Esclarecimento e Regularidade a respeito do mesmo, manter as taxas glicêmicas controladas e estar atento a casos de gravidez, pelo fato da teratogenicidade.

Diante dos fatos expostos se faz necessário um tratamento e acompanhamento adequado com a participação de uma equipe multidisciplinar e inclusão relevante do farmacêutico, já que o mesmo é quem conhece a farmacologia do medicamento, seus efeitos adversos e interações.

\section{REFERENCIAS BIBLIOGRÁFICAS}

ALVES, G. C. B; ORSOLIN, P. C; ROCHA, A. A. Efeito modulador do Roacutan® isotretinoína) sobre a carcinogenicidade da doxorrubicina, avaliado por meio do teste para detecção de clones de tumores epiteliais em Drosophilamelanogaster. Revista Perquirere, v. 12, n. 2, p. 201-212, dez, 2015. 
BOUZAS, I; MENESES, C. Acne vulgar e adolescência. Adolescência e Saúde, Rio de Janeiro, v. 6, n. 3, p.21-23, set. 2009.

BRASIL, AGÊNCIA NACIONAL DE VIGILÂNCIA SANITÁRIA. Isotretinoína, 2018. Disponível em:

http://www.anvisa.gov.br/datavisa/fila_bula/frmVisualizarBula.asp?pNuTransacao=17 74352018\&pldAnexo=10476303. Acesso em: agosto de 2019.

BRASIL, IBGE, Instituto Brasileiro de Geografia e Estatística (2009). Acne na população jovem brasileira. Acesso em: maio de 2019.

BRASIL. Agência Nacional de Vigilância Sanitária. Portaria n`344, de 12 de maio de 1998. Aprova o Regulamento Técnico sobre substâncias e medicamentos sujeitos a controle especial. Disponível em:

<http://portal.anvisa.gov.br/wps/wcm/connect/9c7e4880474597069f52df3fbc4

BRASIL, Agência Nacional de Vigilância Sanitária. Protocolo de uso da isotretinoína no tratamento da acne grave, 2015, a.

BRASIL, Agência Nacional de Vigilância Sanitária. Portaria n.1159, de 18 de novembro de 2015, b.

BORGES, M.B., et al, 2011. Avaliação laboratorial do perfil lipídico e testes de lesão hepatocelular em pacientes com acne vulgar sob uso de isotretinoína oral. Revista Brasileira Clínica Médica. São Paulo, v. 9, n. 6,p.397-402,nov/dez, 2011.

BRITO, M, F. M., et al. Avaliação dos efeitos adversos clínicos e alterações laboratoriais e, pacientes com acne vulgar tratados com isotretinoína oral. Anais Brasileiros de Dermatologia, v. 85, n. 3, p. 331-337, 2010.

CAJUEIRO, E. S.; LIMA, L. B. R.; PARTATA, A. K. Isotretinoína e suas propriedades farmacológicas. Revista Científica do ITPAC, v. 7, n. 1, p. 1-16, jan, 2014.

CARVALHO, L. J. A.; CARVALHO, L. A. Benefícios da isotretinoína no tratamento da acne nódulo-cística em pacientes hiperandrogênicas devido à síndrome dos ovários policísticos. Revista Medicina Cutâneo IberoLatinoAmericana, v. 33, n. 5, p. 211218, 2005.

DAMASCENA, R. S. PEREIRA, W. G. O. Avaliação dos Potenciais Efeitos Adversos em Pacientes em Uso de Isotretinoína oral para o Tratamento de Acne Vulgar: Uma Revisão Bibliográfica. Revista Multidisciplinar e de Psicologia, v. 11, n. 35, maio, 2017. Disponível em: <https://idonline.emnuvens.com.br/id/article/view/714/1016>. Acesso em: 15 de maio de 2019.

DINIZ, D.G. A. et al. Isotretinoína: perfis farmacológico, farmacocinético e analítico. Revista Brasileira de Ciências Farmacêuticas, v.38, n.4, out/dez, 2002.

DINIZ, D.G. A. e tal. Isotretinoína: perfis farmacológico, farmacocinético e analítico. Revista Brasileira de Ciências Farmacêuticas, v.38, n.4, out/dez, 2014. 
FREITAS, L. D; SANTOS, E. N. Atenção farmacêutica e o uso da isotretinoína. Instituto Pharmacológica. Goiânia, 1997. Disponível em:

http://www.cpgls.pucgoias.edu.br/6mostra/artigos/SAUDE/LEANDRO\%20DINIZ\%20 FREITAS.pdf. Acesso em: 15 de maio 2019.

KOLBE, A.C; SILVA, F.L. Uso da isotretinoína no tratamento da acne e sua relação com a halitose. Revista de Ciências Médicas e Biológicas. Salvador, v. 16, n. 1, p. 101-105, jan./abr. 2017.

KNUTSON, K; PERSHING, L. K. Medicamentos Tópicos. A ciência e a prática da farmácia. 20. ed. Rio de Janeiro: Guanabara Koogan. Cap. 65, p. 1262 - 1263, 2004.

MENDES et al. Efeitos do uso da Isotretinoína e Acitretina nos tecidos bucais Revisão de Literatura. Arquivo Brasileiro de Odontologia, v.12 n.1, 2016.

MENDES, et al. Efeitos do uso da isotretinoína e Acitretinoina nos tecidos bucais, 2016.

MINAYO, M. C. de S. O desafio do conhecimento. 10. ed. São Paulo: HUCITEC, 2007.

NAST, A.; BAYERL, C.; BORELLI, C. et al. S2k-leitlinie zurtherapie der akneS2kguideline for therapy of acne. Journal of the German Society of Dermatology, v.8, n. 2, p. 59, 2010.

SETTE, I. M. F. et al. Isotretinoína no tratamento da acne: riscos $\mathrm{x}$ benefícios. Revista Brasileira Farmacêutica, v. 90, n. 3, p. 186-189, 2009.

SALOMAO, P. E. A. et al. As Tecnologias de Informação e Comunicação (TIC) no ensino superior. Revista Multidisciplinar do Nordeste Mineiro, v. 1, 2018.

SILVA, L.N. et al. Acompanhamento farmacoterapêutico do uso da isotretinoína: um estudo de caso. Revista Faculdade Montes Belos (FMB), v. 7, n. 1, p. 121-135, 2014. Disponível em: <file:///C:/Users/lugob/Downloads/113-442-1-PB.pdf>. Acesso em: 10 de abril de 2019. 